\title{
Modeling of Physiology Based Toxico-Kinetics and Toxico-Dynamic to Diagnose Acute Effects of Nicotine on Heart Rate
}

Helen $\mathrm{R}$ and Uma CHS*

Department of EEE, Thiagarajar College of Engineering, Madurai, Tamil Nadu, India

\begin{abstract}
In modern world persons addicting to drugs are increasing gradually. Smoking, cocaine, nicotine etc. are harmful to human body. The most commonly affected organs are lung, liver, kidney. But the effect of nicotine is more in lungs which affect blood concentration and heart rate, analyzed using Physiologically Based Toxico-Kinetics and Physiologically Based Toxico-Dynamics modeling. The person affected by heart disease also has chance for lung failure. Best and safe method for avoiding lung failure is lung transplantation and fixing Artificial Lung (AL). In lung transplantation both the donor and recipient requirement should perfectly match, in Artificial Lung method any one of the lung assisting device is fixed instead of original lungs, but it is not analyzed effectively. In order to improve its efficiency the compliance chamber is designed and kept in between heart and lungs. By which the pulmonary artery pressure is maintained in the range between 8 to $25 \mathrm{~mm} / \mathrm{Hg}$.
\end{abstract}

Keywords: Physiology based toxico-kinetics; Physiology based toxico-dynamics; Artificial lungs; Lung transplantation; Compliance chamber

\section{Introduction}

Tobacco which is particularly smoked product has been associated with great harm and growing public disapproval and can be expected to suffer in the market place. This situation has created opportunities for other less harmful nicotine containing products causes immediate effect on cardio vascular disorders and delayed effect on respiratory and cancer disorders [1]. The straw nicotine oral delivery system is a novel form of nicotine replacement theraphy designed to provide not only nicotine but also oral and manual stimulation and ease of dosing. The straw is the single-use. Drinking straw containing loose nicotine bitartrate particles that are ingested with the first sip of beverage. Straw may be a useful new tool in supporting smoking cessation for several reasons [2]. The absorption of nicotine delivered by a transdermal delivery system (tedious) was investigated in two separate studies, single dose proportionality study and multiple dose study. The Area Under Curve (AUC) and Maximum Concentration (Cmax) values are proportional to the dose. Transdermal delivery provides continuous absorption of drug through stratum corneum even during sleep [3]. Sympathetic over activity is implicated in the increased cardiovascular risk of cigarette smokers. Excitatory nicotine receptors are present on peripheral chemoreceptor.

Chemoreceptors located in the carotid and aortic bodies increase Ventilation (Ve), Blood Pressure (BP), Heart Rate (HR) and Sympathetic Nerve Activity to Muscle circulation (MSNA) in response to hypoxia. Nicotine Replacement Technique (NRT) increases myocardial oxygen consumption in periods of reduced oxygen availability [4]. The Pharmaco-Kinetic and Hemo-Dynamic effects of nicotine patch are significantly different between smokers and nonsmokers. The Hemodynamic effects of the nicotine patch on blood pressure and heart rate were greater in nonsmokers than in smokers, and the parasympathetic effects such as nausea and vomiting occurs more frequently in nonsmokers than in smokers [5].

The physiologically based Toxico-Kinetic model treats the time course of chemical distribution. It is illuminating to use fugacity to directly examine the relative equilibrium status of compartments and to provide the direct estimate of chemical activity thus with suitable parameterization it has potential for both bio-concentration and toxicity expressed as median lethal concentrations, critical body residues, and chemical activity as a function of time to death [6]. The Physiologically Based Toxico-Kinetics (PBTK) and Toxico-Dynamic modeling (PBTD) was applied to provide concentration time profiles of nicotine. This model is used to estimate the heart rate in terms of maximum concentration based on inhalation, oral intake and absorption. The Toxico-Dynamic model is used to analysis the effect of nicotine in heart rate and the Toxico-Kinetic model is used to analyze the effect of nicotine in different organs of our body (kidney, liver, lung). Lungs are mainly affected during smoking [7].

Artificial lungs may serve as transplant alternatives to patient with respiratory failure. To provide the pulmonary replacement, the device cannot significantly alter right ventricular after load. Addition of a compliance chamber reduces pulse wave reflection and normalizes ventricular function. The pulmonary replacement with the lowresistance artificial lung is tolerated by the right ventricular in this short term model [8]. Matching the impedance of an artificial lung for pulmonary replacement to native pulmonary impedance is important in preventing right ventricular dysfunction. The lunged parameter model and the bench top simulation will aid in the design and testing of compliance chamber modification to improve its efficiency [9-12]. The contribution of this paper gives the detailed analysis of changes in blood concentration according to the nicotine dosages in liver and kidney using Physiologically Base Toxico-Kinetics (PBTK) modeling and heart rate changes based on using Physiologically Based ToxicoDynamic modeling (PBTD) and cardiac output is determined. Based on this changes the lung is mainly affected which is demonstrated in

*Corresponding author: Uma $\mathrm{CH}$, Department of EEE, Thiagarajar College of Engineering, Madurai, Tamil Nadu 625015, India, Tel: 9443076847; E-mail: umakvp4@gmail.com

Received: October 21, 2017; Accepted: October 31, 2017; Published: November 05, 2017

Citation: Helen R, Uma CHS (2017) Modeling of Physiology Based ToxicoKinetics and Toxico-Dynamic to Diagnose Acute Effects of Nicotine on Heart Ra. J Bioengineer \& Biomedical Sci 7: 238. doi: 10.4172/2155-9538.1000238

Copyright: @ 2017 Helen R, et al. This is an open-access article distributed under the terms of the Creative Commons Attribution License, which permits unrestricted use, distribution, and reproduction in any medium, provided the original author and source are credited. 
relation between heart rate, cardiac output and blood flow. As a result of fixing artificial lungs that is, assisting device for lungs which is replaced instead of original lungs. Every device has certain original efficiency. In order to increase its efficiency, a compliance chamber is designed and fixed.

\section{Nicotine Dosage Used}

The dosages were selected for resting condition to show the difference in heart rate changes, blood concentration and cardiac output at identical concentration levels of nicotine. The selected dosing conditions for nicotine with web and literature references are mentioned in Table 1.

\section{Physiological Modeling}

\section{Physiologically based toxico-kinetic modeling (PBTK)}

In this model the drug concentration profile result from the uptake and elimination capacity of organ composing the body, the distribution of the drug to an organ depends on the blood flow to the organ, the organ weight and the partition coefficient of the drug between the blood and the organ, the major distribution takes place in liver, GI tract and kidney. The block representation of the PBTK model is represented in Figure 1.

Liver and GI tract: The model equations for the liver and GI tract are given:

$$
\begin{aligned}
& \text { Liver: } \\
& \frac{d \text { Aliv }}{d t}=\text { Flgit }+ \text { FORMliv }+ \text { Fliv. }\left(\text { Cart }-\frac{\text { Cliv }}{\text { PCliv }}\right)-\text { METliv } \\
& \text { Cliv }=\frac{\text { Aliv }}{\text { Vliv }}
\end{aligned}
$$

\section{GI tract:}

(3)

$$
\begin{aligned}
& \text { Cstm }=\frac{\text { Astm }}{\text { Vstm }} \\
& \text { Csi }=\frac{\text { Asi }}{\left(\frac{3}{4}\right) \text { Vint }} ; \\
& \text { Cli }=\frac{\text { Ali }}{\left(\frac{1}{4}\right) \text { Vint }}
\end{aligned}
$$

\begin{tabular}{|c|c|}
\hline Types & Dosage level \\
\hline \multicolumn{2}{|c|}{ Cigarettes (1.2 mg) } \\
\hline 3 per day & $3.6 \mathrm{mg}$ \\
\hline 8 per day & $9.6 \mathrm{mg}$ \\
\hline 14 per day & $16.8 \mathrm{mg}$ \\
\hline 21 per day & $25.2 \mathrm{mg}$ \\
\hline \multirow{3}{*}{ Dermal patches } & $7 \mathrm{mg}$ \\
\hline & $14 \mathrm{mg}$ \\
\hline & $21 \mathrm{mg}$ \\
\hline \multicolumn{2}{|c|}{ Nicotine lozenges } \\
\hline $2 \mathrm{mg}$ for every $2 \mathrm{~h}$ & $24 \mathrm{mg}$ \\
\hline $2 \mathrm{mg}$ for every $1 \mathrm{~h}$ & $48 \mathrm{mg}$ \\
\hline $4 \mathrm{mg}$ for every $1 \mathrm{~h}$ & $96 \mathrm{mg}$ \\
\hline
\end{tabular}

Where:

Aliv $=$ amount of nicotine present in liver

Table 1: Nicotine dosage.

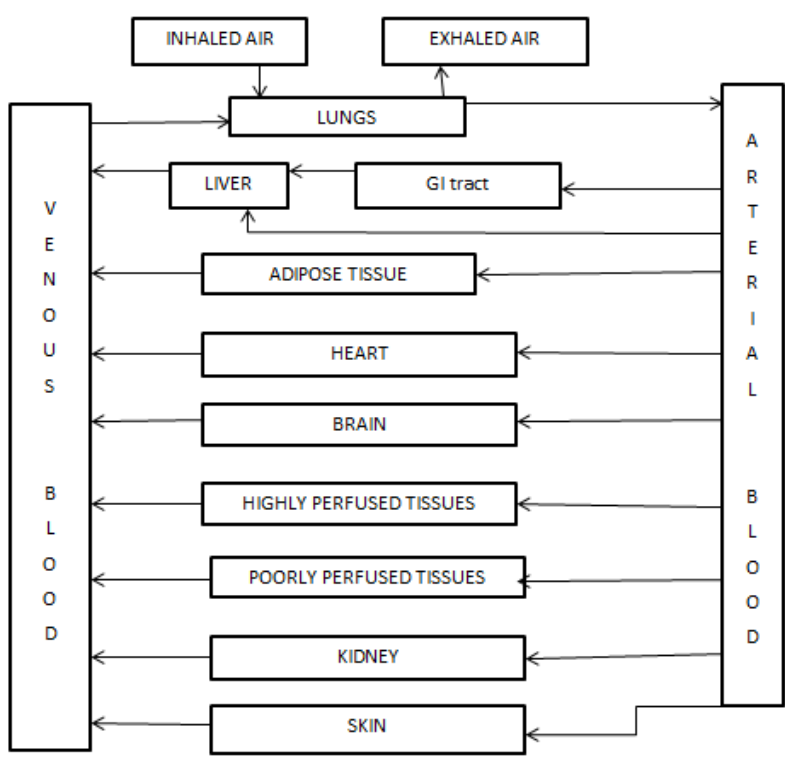

Figure 1: PBTK flow chart.

Fliv $=$ fraction of liver

Cart $=$ concentration present in arteries

PCli $=$ partial coefficient of liver

METliv $=$ metabolism of nicotine in liver

Flgit $=$ GI tract formation

Fra, frb, frc $=$ absorbed fractions that reach liver from stomach, small intestine and large intestine

Fgit $=$ fraction of GI tract

PCgit $=$ Partial Coefficient of GI tract

Cstm $=$ Concentration of nicotine present in stomach

$\mathrm{Csi}=$ Concentration of nicotine present in small intestine

$\mathrm{Cli}=$ Concentration of nicotine present in large intestine

Astm, Asi, Ali = amount of nicotine present in stomach, small intestine and large intestine

Vstm $=$ volume of stomach

Vint $=$ volume of intestine

These parameters values [13-18] are mentioned in Gajewska M et al. [8] and Loizou et al. [16] which are discussed in the references. The volume of the organ is calculated with the information of organ's weight and its density which are tabulated in Table 2. This is specified as the standard values which are assumed for the average body weight of $70 \mathrm{~kg}$. These data are taken from the paper (physiological parameter values for physiologically based pharmacokinetics models published by Brown et al.) (Table 3).

Kidney: The equation for the kidney is given as:

$$
\frac{d \text { Akid }}{d t}=\text { Fkid }\left(\text { Cart }-\frac{\text { Ckid }}{\text { PCkid }}\right)-\operatorname{CLR}\left(\frac{\text { Ckid }}{\text { PCkid }}\right) \text {. }
$$


Citation: Helen R, Uma CHS (2017) Modeling of Physiology Based Toxico-Kinetics and Toxico-Dynamic to Diagnose Acute Effects of Nicotine on Heart Ra. J Bioengineer \& Biomedical Sci 7: 238. doi: 10.4172/2155-9538.1000238

Page 3 of 8

\begin{tabular}{|c|c|}
\hline Parameters & Values \\
\hline Fliv & 0.254 \\
\hline Fgit & 0.025 (man) \\
\hline Fra & 0.0265 (woman) \\
\hline Frb & 0.2 \\
\hline Frc & 0.6 \\
\hline PCgit & 0.2 \\
\hline Cstm & 0.81 \\
\hline Csi & Varies \\
\hline Cli & Varies \\
\hline Cart & Varies \\
\hline FORMliv & 0.8 \\
\hline Cliv & 0 \\
\hline PCliv & 0.0061 \\
\hline METliv & 0.81 \\
\hline & 0.1674 \\
\hline
\end{tabular}

Table 2: Parameters of TK model.

\begin{tabular}{|c|c|}
\hline Organs name & \% of body Weight \\
\hline Stomach & 0.21 \\
\hline Small intestine & 0.91 \\
\hline Large intestine & 0.53 \\
\hline GI & 1.71 \\
\hline Kidney & 0.44 \\
\hline Heart & 0.47 \\
\hline Lungs & 0.76 \\
\hline
\end{tabular}

Table 3: Weight of organs.

$$
\text { Ckid }=\left(\frac{\text { Akid }}{\text { Vkid }}\right)
$$

Where:

Akid $=$ Amount of nicotine present in kidney

Fkid $=$ blood flow rate through kidney

\section{Ckid $=$ concentration of nicotine}

The standard values of kidney parameters are mentioned by Gajewska M et al. [8,19]. Thus from the above information the modeling of kidney is done and the amount of changes in blood concentration for each organ is evaluated, based on the value of nicotine dosage given into our body, the amount of nicotine that can be distributed to the organ can be estimated (Table 4).

\section{Physiologically based toxico-dynamic modeling (PBTD)}

The PBTD model explanation is outined in Fattinger et al. [7,2022]. Here venous blood concentration play a vital role. Using PBTD the model for heart rate was developed. Here modification is necessary for the case of nicotine affected during exercise only. The block diagram for PBTD model is given in Figure 2.

The above block diagram gives the better fit and better description for the pharmacological response. Here for avoiding some issues one assumption is taken that the chemical concentration in blood(Cven) is always much less than the concentration needed to produce half of the maximal effect (Cven,50) (i.e.,) Cven $<<<<$ Cven,50. The antogonist formation and elimination rates are assumed to be contant and are dependent on venous blood concentration. The equation for the PBTD model is given as:

\begin{tabular}{|c|c|}
\hline Parameters & Values \\
\hline Fkid & 0.19 (woman) \\
& 0.2 (man) \\
\hline Akid & Varies \\
\hline PCkid & 1.34 \\
\hline Cart & 0.8 \\
\hline CLR & 0.036 \\
\hline
\end{tabular}

Table 4: Parameters value for kidney.

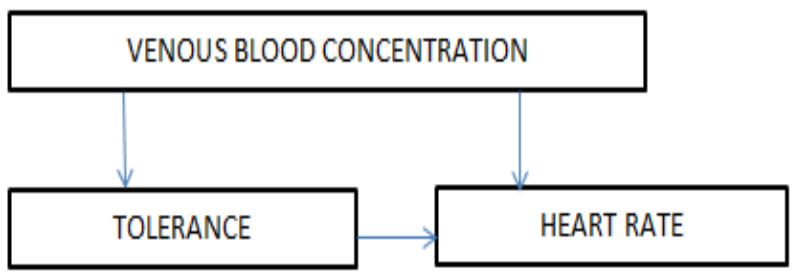

Figure 2: PBTD model.

$$
E=\mathrm{E} 0+\frac{\left(\frac{\text { Emax }}{\text { Cven }}\right) \cdot C^{y} \text { ven }}{\left(1+\frac{c^{y} \text { ant }}{C^{y} \text { ant }, 50}\right)\left(1+\frac{c^{y} \text { ven }}{c^{y} \text { ven, } 50}\right)}
$$

$$
E=E 0+\frac{(\mathrm{s}) \cdot \mathrm{c}^{\mathrm{y}} \text { ven }}{\left(1+\frac{\mathrm{c}^{\mathrm{y}} \text { ant }}{\mathrm{c}^{\mathrm{y}} \text { ant }, 50}\right)}
$$

$$
\text { Vven. } \left.\left(\frac{d \text { Cant }}{d t}\right)=\text { Ka, ant.(fu.Cven }\right)- \text { Kel, ant.Cant }
$$

Where:

Ven $=$ Venous blood

Cant $=$ Concentration of antagonist

Ka,ant; Kel,ant $=$ Formation and elimination rates of antagonist

$\mathrm{Fu}=$ Free fraction of a stimulant

$\mathrm{E}=$ Effect on heart rate

$\mathrm{E} 0=$ Base line effect

Emax $=$ Maximal effect

$S=$ Ratio of Emax

Cven $=$ venous blood concentration

The parameter used are mentioned by Porchet et al. in his paper $[20,23,24]$. Thus from the above information the modeling is done and the amount of changes in heart rate is determined, based on the value of nicotine dosage given into our body, the amount of nicotine that can be distributed can also be found out. These two modeling are used only for analyzing purposes. Thus the acute effect of nicotine in each organ and heart rate can be determined using this modeling (Table 5).

\section{Relation Equation}

The heart rate and the blood flow both are indirectly related. During 


\begin{tabular}{|c|c|}
\hline Parameters & Values \\
\hline Cven & Varies \\
\hline Eo & 61.2, 64(at rest) 145 (during exercise) \\
\hline S & 1000 \\
\hline Ka,ant & 3 \\
\hline Kel,ant & 6 \\
\hline Cant,50 & 0.00772 \\
\hline Y & 1(rest) 0.6(during exercise) \\
\hline
\end{tabular}

Table 5: Parameters of PBTD model.

inspiration the lungs will expand and during expiration process the lungs will contract. Consequently in heart during inspiration there will be increase in heart rate and during expiration there will be decrease in heart rate. During intake of nicotine mostly the ventricle of the heart is affected. Hence ventricular assisting device (VAD) is used. The output from the VAD is given to the lungs thus the input to the lungs depends on the output from the VAD (i.e.,) ventricle of heart. The following equation gives the relation between heart rate and pressure.

\section{$\mathrm{P}=\mathrm{SV}^{\star} \mathrm{HR}^{\star} \mathrm{TPR}(9)$}

$\mathrm{BF}=\mathrm{P} / \mathrm{R}(10)$

Where

$\mathrm{P}=$ Pressure

$\mathrm{SV}=$ Stroke Volume

$\mathrm{HR}=$ Heart Rate

TP $=$ Total Pressure Resistance

\section{$\mathrm{R}=$ Resistance}

$\mathrm{BF}=$ Blood Flow

The cardiac output $(\mathrm{Q})$ is termed as the total volume of blood being pumped from heart ventricle in minute (ie) blood leaves from the left ventricle every minute. At average resting time the cardiac output will be $5 \mathrm{~L} / \mathrm{min}$ and during exercise time it will be $4-7$ times higher than rest.

$$
\mathrm{CO}=\mathrm{SV} \times \mathrm{HR}
$$

The stroke volume (SV) is defined as the volume of blood ejected from heart ventricle with each beat at average resting time the stroke volume will be $60-70 \mathrm{ml} / \mathrm{beat}$. The heart rate (HR) determines the number of times heart pumps in 1 minute. At average resting time the heart rate will be $60-100 \mathrm{bpm}$ (beats per minute).

\section{Design of Compliance Chamber}

In general compliance means Ability of hollow organ to distend and increase volume with increasing trans-mural pressure to resist coil towards original dimensions on application of a distending or compressing force. It is also recognized as the tendency of arteries and veins to stretch in response to pressure has a large effect on perfusion and blood pressure. It is represented as $\mathrm{C}=\Delta \mathrm{V} / \Delta \mathrm{P}$.

Where

$\mathrm{C}=$ compliance

$\Delta \mathrm{V}=$ change in volume

$\Delta \mathrm{P}=$ change in pressure

Here three element lumped parameter model is used to implement compliance chamber. The circuit consist of compliance element $\left(\mathrm{C}^{\star}\right)$ and the resistive elements $\left(\mathrm{R} 1^{\star}, \mathrm{R} 2^{\star}\right)$ before and after the $\mathrm{C}^{\star}$

The design of compliance chamber is outlined by the following equations

$$
\begin{aligned}
\mathrm{P}^{\star} & =\left(\mathrm{R} 1^{\star}+\mathrm{R} 2^{\star}\right) \mathrm{Qref} \\
\mathrm{Q}^{\star} & =\mathrm{Qref} \mathrm{Q} \\
\mathrm{Ri}^{\star} & =\left(\mathrm{R} 1^{\star}+\mathrm{R} 2^{\star}\right) \mathrm{Ri} \\
\mathrm{T}^{\star} & =\text { Tpulse }{ }^{\star} \mathrm{t}
\end{aligned}
$$

Where:

$\mathrm{P}^{*}=$ pressure across the compliance element

Tpulse $=$ period of pulsatie flow

$\mathrm{T}=$ ratio of the time scale of oscillatory flow

$\mathrm{R}=$ total resistance in compliance chamber

Qref=maximum value of periodic inlet flow

Q1= flow of blood in cardiac output

$\mathrm{Q} 2=$ flow of blood in pulmonary vein

$\mathrm{P} 1=$ pulmonary artery pressure

P2 = Left auricle pressure $(10 \mathrm{~mm} / \mathrm{Hg})$

From this the right ventricle pressure which is to be given for lungs as input is determined. which should have the range from $9 \mathrm{~mm} / \mathrm{Hg}$ to $21 \mathrm{~mm} / \mathrm{Hg}$.

\section{Heart-Lung Block}

The lung plays a major role in respiration; the purification of blood process is carried out in the lungs. The respiratory model for the human lungs is more complex. When there is the problem in lungs most of people undergoes, lung transplantation. But this process will get succeeded only when both the donor and receptor requirements matches. Hence the next developed system is fixing an artificial lung that is the assisting device which do all the work instead of lungs. The right side of a human heart play an important role, it's function is to collect a blood that contain oxygen and carbon dioxide from the body and transfer it to the lungs and lungs collect all the oxygen and releases carbon dioxide. Now the left side of the heart collects bloods that contain a lot of oxygen from the lungs and then transfer it to the different part of the body.

The model for the combination of heart and lung is done in which the cardiac output is given. The equation for all of the elements are then combined using continuity and the requirement that the total pressure drop along the circuit equal p1-p2. The model of heart lung block is shown in the Figure 3. The non-dimensional governing equation of the system is given as:

$$
\begin{aligned}
& \frac{\mathrm{dP} 1(\mathrm{t})}{\mathrm{dt}}=-\mathrm{T} \frac{\mathrm{P} 1(\mathrm{t})}{1-\mathrm{R}}+\mathrm{TQ} 1(\mathrm{t})\left(1+\frac{\mathrm{R}}{1-\mathrm{R}}+\mathrm{R} \frac{\mathrm{dQ} 1(\mathrm{t})}{\mathrm{dt}}\right. \\
& \mathrm{Q} 2=\mathrm{Q} 1-\mathrm{T} \frac{\mathrm{dP} 1}{\mathrm{dt}}+\left(\frac{R}{\mathrm{~T}}\right) \frac{\mathrm{dQ} 1}{\mathrm{dt}}
\end{aligned}
$$

Where;

$\mathrm{P} 1=$ pulmonary artery pressure 
Q1=flow of cardiac output

$\mathrm{P} 2=$ left atrial pressure $(10 \mathrm{~mm} / \mathrm{Hg})$

Q2=flow in pulmonary vein

$\mathrm{T}=$ time period

From this the pressure of heart $\mathrm{P} 1$ is determined for every change in the cardiac output. This is given as the input to the compliance chamber and the assisting device.

\section{Results and Discussion}

\section{Analysis}

Analysis for liver and kidney using PBTK modeling: Based on the PBTK modeling which is represented in the equations $(1,2,3,4)$

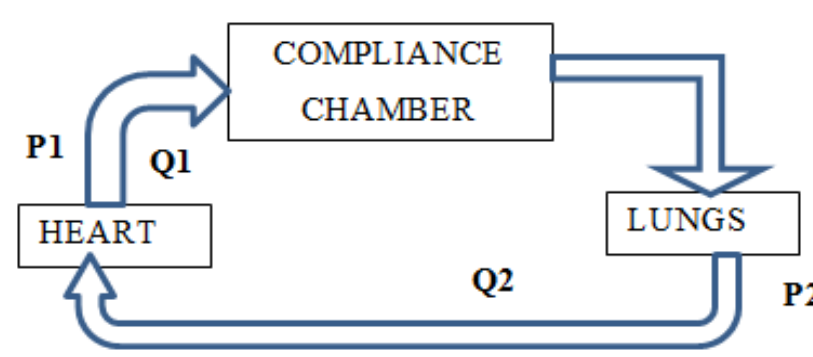

Figure 3: Heart-lung model.

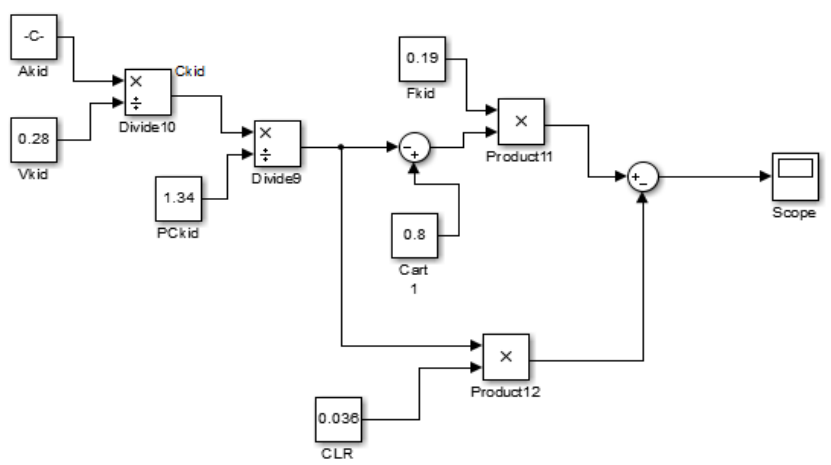

Figure 4: Modeling of kidney.

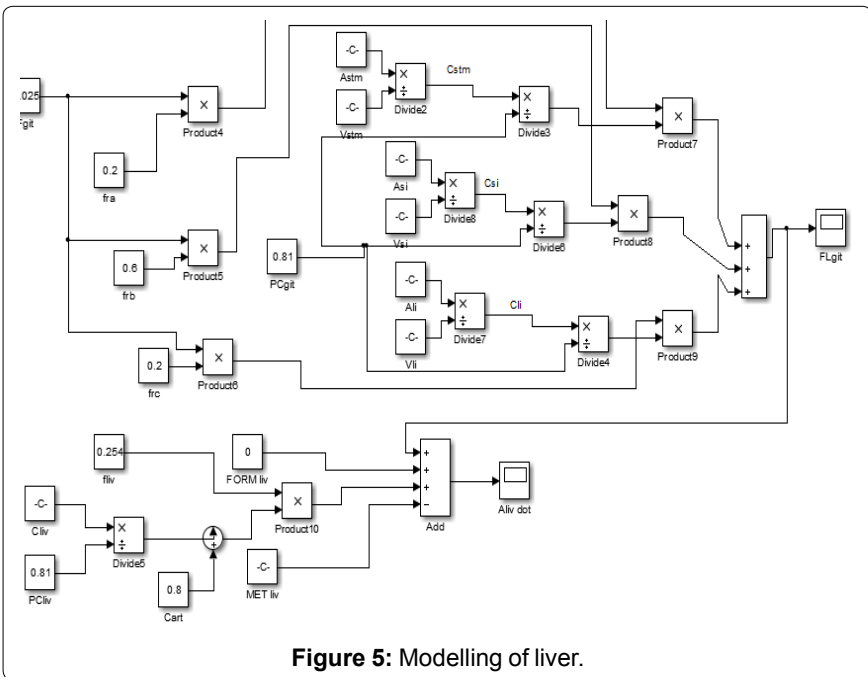

and Figure 1 the simulation is performed in MATLAB/Simulink that is given in Figures 4 and 5 the analysis is carried out. The analysis is done in order to find out the impact of nicotine in blood concentration of different organs (liver and kidney). The graphical representation of analysis shown in Figure 6, the X-axis represents the types of dosages and the $y$-axis represents the blood concentration values of both liver and kidney. It is clearly conveys that while increasing the dosage level the blood concentration increases and the impact of nicotine is more in kidney than in liver but while comparing with lungs the impact is greater in lungs.

Analysis of heart rate using PBTD modeling: Based on PBTD modeling represented in the equations 6, 7,8 and Figure 2 the simulation is performed and given in Figure 7 the analysis is done. This analysis is to identify the heart rate changes. The graphical representation of analysis is shown in Figure 8 where the $\mathrm{x}$-axis represents the dosages and the $y$-axis represents the heart rate while increasing the dosage level the heart rate also increased.

\section{Modeling:}

PBTK modeling: The Physiology Based Toxico-Kinetic modeling is simulated for both liver and kidney using MATLAB/Simulink. The simulation is given in Figure 4 for kidney and Figure 5 for liver and their respective output is presented in the Figures 9 and 10. The analysis

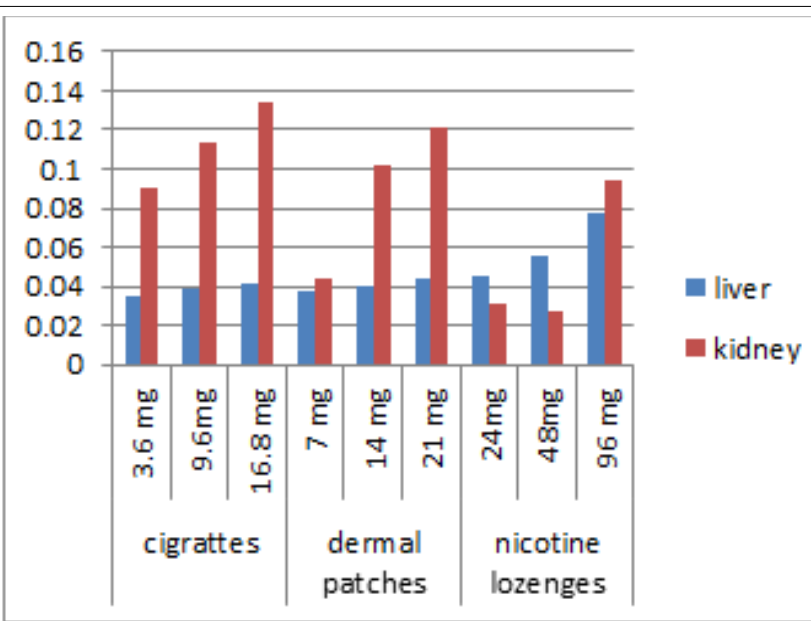

Figure 6: Blood concentration analyses.

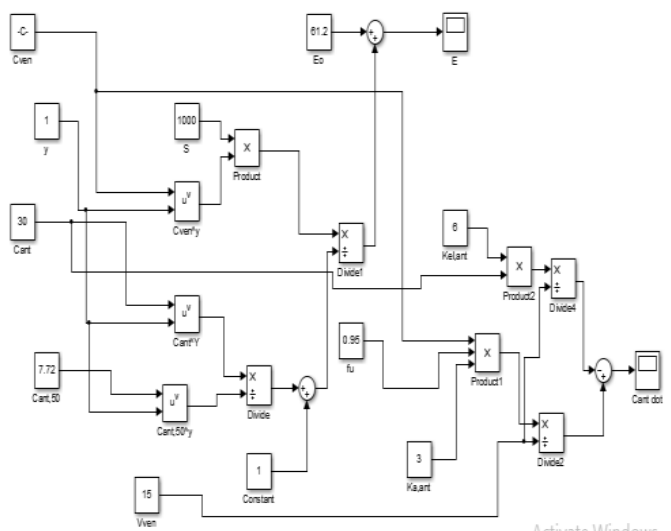

Figure 7: PBTD model. 
Citation: Helen R, Uma CHS (2017) Modeling of Physiology Based Toxico-Kinetics and Toxico-Dynamic to Diagnose Acute Effects of Nicotine on Heart Ra. J Bioengineer \& Biomedical Sci 7: 238. doi: 10.4172/2155-9538.1000238

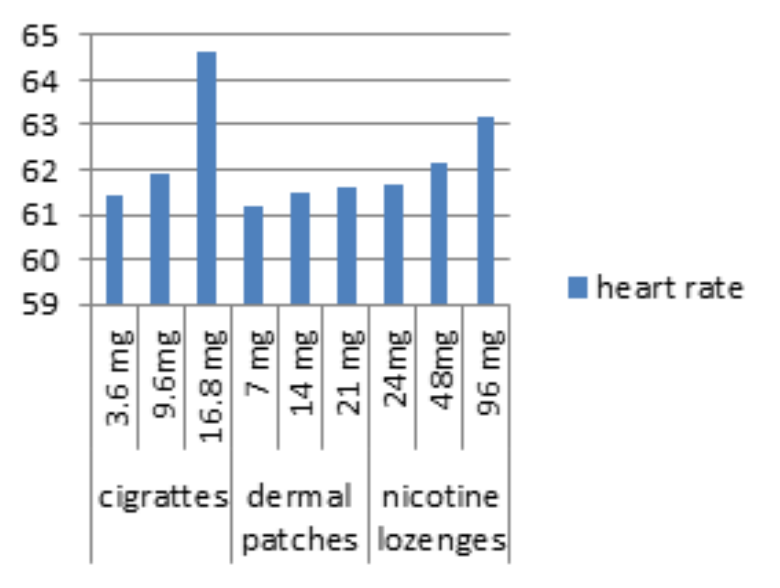

Figure 8: Heart rate analyses.

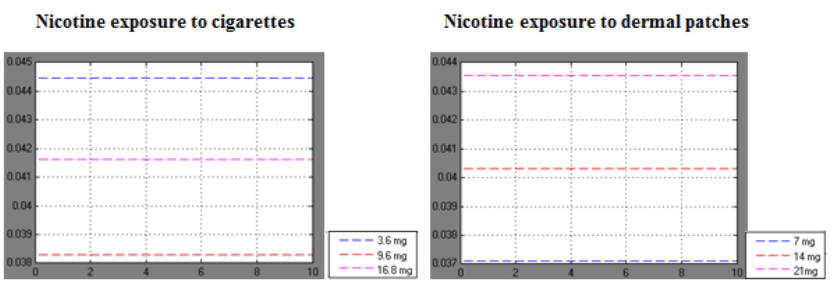

Nicotine exposure to nicotine lozenges

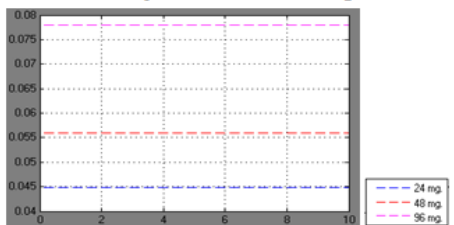

Figure 9: Simulation result for kidney at various nicotine dosages.

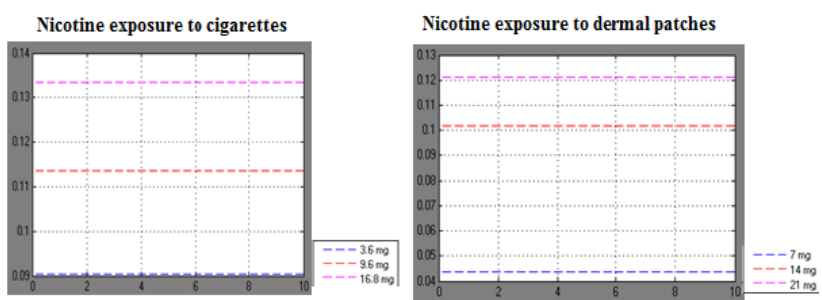

Nicotine exposure to nicotine lozenges

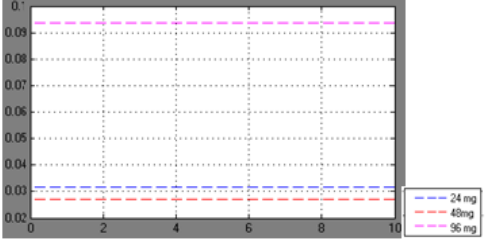

Figure 10: Simulation for liver at various dosages.

is also determined for blood concentration based on this which is explained in the analysis part of figure.

As a result from this modeling it is analyzed that the concentration of blood increases. In our human body, generally the concentration of

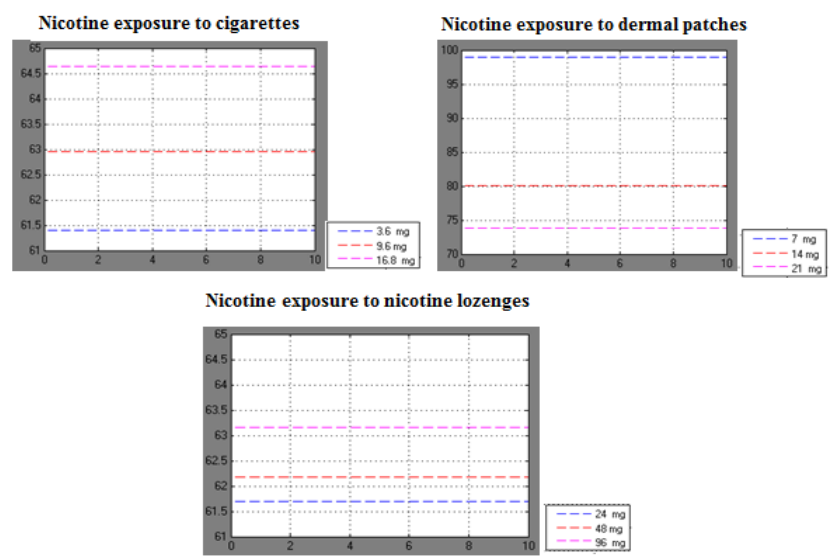

Figure 11: Simulation result for PBTD modelling

\begin{tabular}{|c|c|c|c|c|}
\hline \multirow{2}{*}{} & PBTK (Blood Concentration In & \multicolumn{2}{|c|}{$\begin{array}{c}\text { PBTD (Parameters Of } \\
\text { Organs) }\end{array}$} \\
\cline { 2 - 5 } & Liver & Kidney & Heart rate & $\begin{array}{c}\text { Cardiac } \\
\text { Output }\end{array}$ \\
\hline \multicolumn{5}{|c|}{ Cigrattes(1.2 mg) } \\
\hline $3.6 \mathrm{mg}$ & 0.0355 & 0.09026 & 71.27 & 4.704 \\
\hline $9.6 \mathrm{mg}$ & 0.0383 & 0.1135 & 71.4 & 4.712 \\
\hline $16.8 \mathrm{mg}$ & 0.0416 & 0.1334 & 74.64 & 4.926 \\
\hline & \multicolumn{5}{|c|}{ Dermal patches } \\
\hline $7 \mathrm{mg}$ & 0.0371 & 0.04376 & 71.2 & 4.699 \\
\hline $14 \mathrm{mg}$ & 0.0403 & 0.1019 & 71.49 & 4.718 \\
\hline $21 \mathrm{mg}$ & 0.0435 & 0.1213 & 72.06 & 4.756 \\
\hline & & Nicotine lozenges \\
\hline $24 \mathrm{mg}$ & 0.045 & 0.03168 & 71.69 & 4.732 \\
\hline $48 \mathrm{mg}$ & 0.056 & 0.02716 & 72.18 & 4.764 \\
\hline $96 \mathrm{mg}$ & 0.078 & 0.09358 & 73.16 & 4.829 \\
\hline & &
\end{tabular}

Table 6: PBTD and PBTK model.

blood should be minimum so that the blood can flow easily. Otherwise it will be very difficult for the blood to move freely. Because of this the organs are not supplied with rich oxygenated blood. Hence there may dis-function occurs. Thus the increased amount of nicotine intake affect the liver and kidney. They can't be able to do their proper function.

PBTD modeling: The Physiology Based Toxico-Dynamic modeling is simulated in MATLAB/Simulink. Here the simulation is done for occurring the heart rate which is represented in Figure 7 and their respective simulation output is given in Figure 11. As a result from this modeling it is analyzed that the rate of heart rate increases gradually based on the nicotine intake.

Table 6 comprises of all the information about the effect of blood concentration in liver, kidney and also the changes of heart rate and cardiac output based on nicotine intake which is analyzed in PBTD and PBTK modeling.

Combined heart and lung model: By relating the heart and lungs their modeling is done with the help of MATLAB/ simulink. Here the pressure $\mathrm{P} 1$ (pulmonary artery pressure) is determined which is given as input to the compliance chamber (Figure 12).

Thus the above modeling of heart- lung is simulated based on the equation 17 which is discussed in the paper by Jonathan et al. Before heart-lung model, the pulmonary artery pressure from right ventricle is determined which is given as input to the lung. Figure 8 shows the right 
Citation: Helen R, Uma CHS (2017) Modeling of Physiology Based Toxico-Kinetics and Toxico-Dynamic to Diagnose Acute Effects of Nicotine on Heart Ra. J Bioengineer \& Biomedical Sci 7: 238. doi: 10.4172/2155-9538.1000238

Page 7 of 8

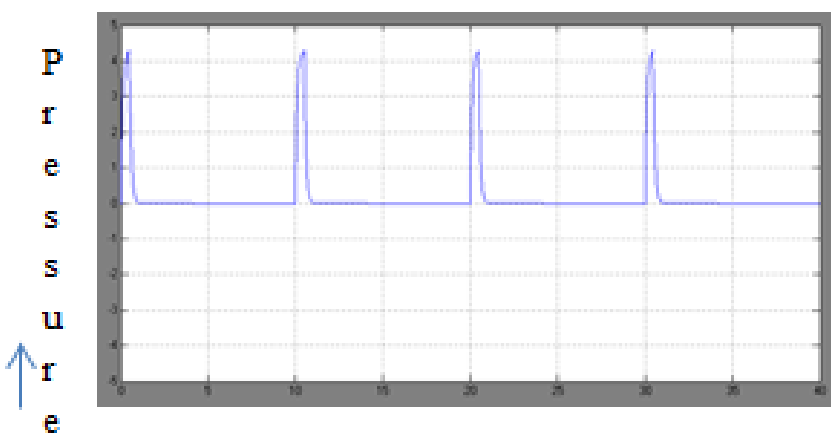

Time

Figure 12: Right ventricular pressure (P1)

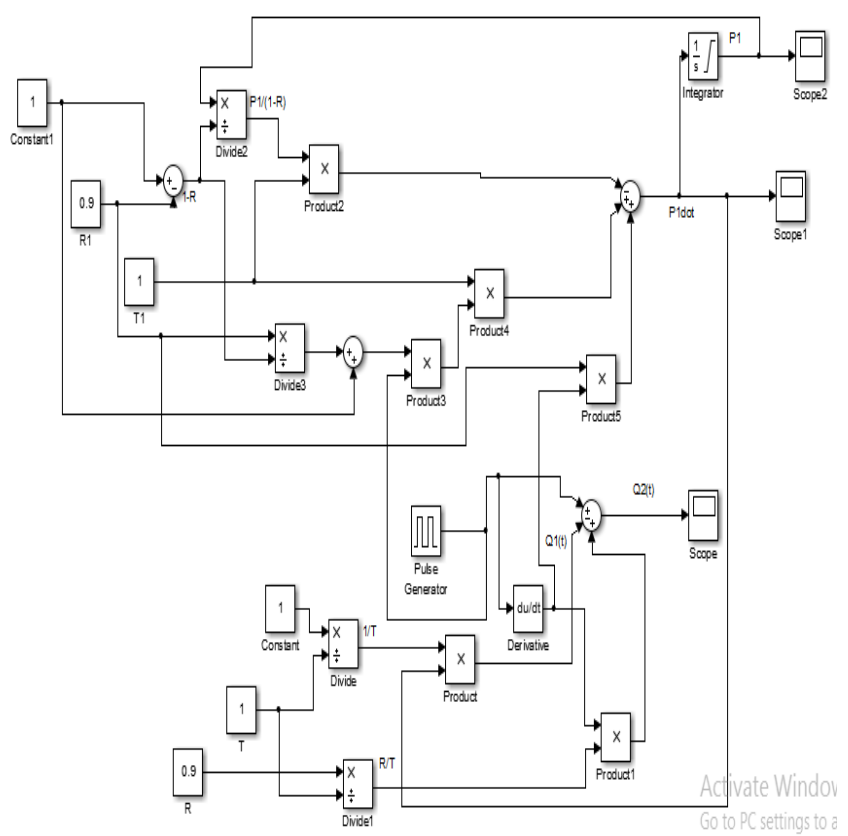

Figure 13: Model for combined heart and lungs.

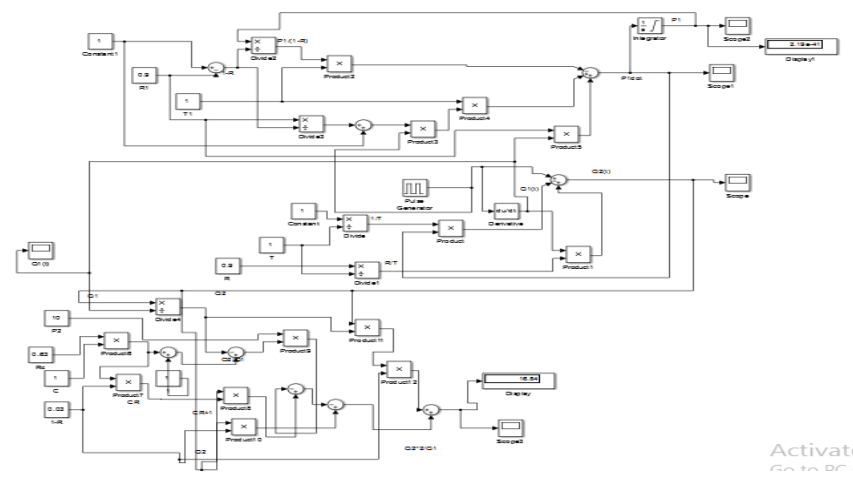

Figure 14: Compliance chamber model along with heart lung.

ventricular pressure with respect to time (P1).

The compliance chamber designing is done in order to increase its efficiency based on the electrical network which is mentioned in the
Figure 13. This compliance chamber is combined along with the heartlung model (Figure 14).

\section{Conclusion}

As a result the acute effect of nicotine in human organs using Physiology Based Toxico-Kinetics (PBTK) and Physiology Based Toxico-Dynamics (PBTD) modeling for various nicotine dosages and their effects on acute increase in blood concentration and heart rate is analyzed, however the effects of smoking on heart rate are definitely higher than any of the investigated methods for nicotine theraphy. The apparent clearance of nicotine was slower in smokers than in nonsmokers. The cardiac output for the analyzed heart rate is determined and the pressure and blood flow from the heart which is given as input to the compliance chamber. The efficiency of the assisting device is increased by means of designing compliance-chamber.

\section{References}

1. Bannon YB, Corish J, Corrigan OI, Devane JG, Kavanagh M, et al. (1989) Transdermal delivery of nicotine in normal human volunteers: a single dose and multiple dose study. Eur J Clin Pharmacol 37: 285-290.

2. Benowitz, Neal L, Florence K, Jacob P (1982) Circadian blood nicotine concentrations during cigarette smoking. Clin Pharmacol Ther 32: 758-764.

3. Brown Ronald P, Delp MD, Lindstedt SL, Rhomberg LR, Beliles RP (1997) Physiological parameter values for physiologically based pharmacokinetic models. Toxicol Ind Health 13: 407-484.

4. Celsie A, Mackay D, Parnis JM, Arnot JA (2015) A fugacity-based toxicokinetic model for narcotic organic chemicals in fish. Environmental Toxicology and Chemistry.

5. Elbourne D, Field D, Mugford M (2002) Extracorporeal membrane oxygenation for severe respiratory failure in newborn infants. Cochrane Database Syst Rev CD001340.

6. Fagerstrom Karl (2005) The nicotine market: an attempt to estimate the nicotine intake from various sources and the total nicotine consumption in some countries. Nicotine Tob Res 7: 343-350.

7. Fattinger K, Verotta D, Benowitz NL (1997) Pharmacodynamics of acute tolerance to multiple nicotinic effects in humans. J Pharmacol Exp Ther 281: 1238-1246.

8. Gajewska M, Worth A, Urani C, Briesen H, Schramm KW (2014) The acute effects of daily nicotine intake on heart rate-A toxicokinetic and toxicodynamic modelling study. Regul Toxicol Pharmacol 70: 312-324

9. Galletti PM, Richardson PD, Snider MT, Friedman LI (1972) A standardized method for defining the overall gas transfer performance of artificia lungs. ASAIO Journal 18: 359-368.

10. Dhanjoo NG, Kah MK, Pasam R, Yi Su (2012) Lung ventilation modeling for assessment of lung status: detection of lung disease and indication for extubation of mechanically-ventilated COPD patients. INTECH Open Access Publisher.

11. Haft JW, Alnajjar O, Bull JL, Bartlett RH, Hirschl RB (2005) Effect of artificial lung compliance on right ventricular load. ASAIO Journal 51: 769-772.

12. Haft JW, Bull JL, Rose R, Katsra J, Grotberg JB, et al. (2003) Design of an artificial lung compliance chamber for pulmonary replacement. ASAIO Journal 49: 35-40.

13. Hlavac M (2004) Windkessel model analysis in MATLAB.

14. D'Orlando KJ, Fox BS (2004) Tolerability and pharmacokinetics of single and repeated doses of nicotine with The Straw, a novel nicotine replacement product. Nicotine Tob Res 6: 63-70.

15. Krüse J, Golden D, Wilkinson S, Williams F, Kezic S, et al. (2007) Analysis, interpretation and extrapolation of dermal permeation data using diffusion based mathematical models. J Pharm Sci 96: 682-703.

16. Loizou GD, Spendiff M (2004) A human PBPK model for ethanol describing inhibition of gastric motility. J Mol Histol 35: 687-696.

17. Mendelson JH, Goletiani N, Sholar MB, Siegel AJ, Mello NK (2008) Effects of 
Citation: Helen R, Uma CHS (2017) Modeling of Physiology Based Toxico-Kinetics and Toxico-Dynamic to Diagnose Acute Effects of Nicotine on Heart Ra. J Bioengineer \& Biomedical Sci 7: 238. doi: 10.4172/2155-9538.1000238

smoking successive low-and high-nicotine cigarettes on hypothalamic-pituitaryadrenal axis hormones and mood in men. Neuropsychopharmacology 33: 749760 .

18. Najem B, Houssière A, Pathak A, Janssen C, Lemogoum D, et al. (2006) Acute cardiovascular and sympathetic effects of nicotine replacement therapy. Hypertension 47: 1162-1167.

19. Phillips R, Lichtenthal P, Sloniger J, Burstow D, West M, et al. (2009) Noninvasive cardiac output measurement in heart failure subjects on circulatory support. Anesth Analg 108: 881-886.

20. Porchet HC, Benowitz NL, Sheiner LB (1988) Pharmaco-dynamic model of tolerance: Application to nicotine. J Pharmacol Exp Ther 24: 231-236.
21. Schmitt W (2008) General approach for the calculation of tissue to plasma partition coefficients. Toxicol in Vitro 22: 457-467.

22. Teeguarden JG, Housand CJ, Smith JN, Hinderliter PM, Gunawan R, et al. (2013) A multi-route model of nicotine-cotinine pharmacokinetics, pharmacodynamics and brain nicotinic acetylcholine receptor binding in humans. Regul Toxicol Pharmacol 65: 12-28.

23. Yamaguchi K, Mitsui T, Aso Y, Sugibayashi K (2008) Structure-permeability relationship analysis of the permeation barrier properties of the stratum corneum and viable epidermis/dermis of rat skin. J Pharm Sciences 97: 43914403.

24. Yun HY, Seo JW, Choi JE, Baek IH, Kang W, et al. (2008) Effects of smoking on the pharmacokinetics and pharmacodynamics of a nicotine patch. Biopharm Drug Dispos 29: 521-528. 